\title{
THE INFLUENCE OF MATERIAL ANISOTROPY AND SPIRAL WELDING ON TENSILE STRAIN CAPACITY OF SPIRAL WELDED PIPELINES
}

\author{
Michiel De Backer, Koen Van Minnebruggen, Wim De Waele \\ Ghent University, Laboratory Soete, Belgium
}

\begin{abstract}
The longitudinal strain capacity of spiral welded pipelines displays to some extents unexplained behaviour. Therefore, they are not (yet) used extensively in offshore applications and harsh conditions, demanding a strain based design. An important factor that influences the tensile strain capacity is the quantity of anisotropy in terms of strength and toughness. Starting from an anisotropic hot rolled highstrength steel skelp, the process of helical forming and post-treating of the pipe adds heterogeneity and changes the level of anisotropy of the product. A parameter that should be examined with respect to anisotropy is the crack driving force, a measure for the toughness of the pipeline steel. Additional to the mode I loading (opening of the crack), the mode III component drives the in-plane shear motion of a crack in the spiral weld when the pipe is subjected to longitudinal deformation. This action, not present in longitudinal welded pipes, shows a decreasing contribution with increasing plasticity. FE simulations have demonstrated a rise of crack driving force in anisotropic cases with respect to an isotropic reference. However, exact data and variation of various parameters, along with experimental testing need to be conducted. The outcome analysis of such simulations and tests can validate existing models, or help create a better understanding of anisotropic and heterogenic influences on the tensile strain capacity of spiral welded pipes.
\end{abstract}

Keywords: Spiral welded pipeline; tensile strain capacity; strain based design; anisotropy; heterogeneity

\section{INTRODUCTION}

The oil \& gas industry is reluctant to use spiral welded pipelines in harsh conditions. For the last decade, usage has increased in onshore areas, and only slightly in offshore applications. Examples are the start of the greatest gas pipeline in Chinese history, the $4000 \mathrm{~km}$ long West-East 40" pipeline project in 2002 [1]. Secondly, some parts of the $3500 \mathrm{~km}$ cross-border crude oil 30" pipeline project in Canada and the USA, commissioned since 2010, contain spirally formed pipes [2].

Their spiral welded counterparts show major (un)examined differences with with respect to buckling, bending, compressive and tensile behavior [3]. Mechanical properties of longitudinal welded pipelines, further called UOE pipes, have extensively been examined.

Full industrial acceptance of spiral welded pipes for harsh environments has not yet been accomplished, because the performance under large longitudinal strains is not well understood [3]-[6]. In 2011, Det Norske Veritas (DNV) has written a state-of-the-art report on spiral welded pipe regulation, design, production, use and inspection [3]. This report indicates which characteristics of spiral welded pipes need to be examined in detail. The spiral weld and the material anisotropy, two effects highlighted and questioned in the report, are the principal subjects of this paper.

Production of spiral welded pipes consists of more than just helical forming of plates. The starting material, hot rolled TMCP plates, have anisotropic microstructures and mechanical properties. Helical forming angles determine the diameter of the pipe and its overall performance capacity. The spiral welding accompanied with this process locally introduces an extra level of heterogenity to the spiral welded pipeline. A post-heattreatment changes the mechanical properties to a more preferred level, like higher yield strength, and less distinct anisotropy or heterogeneity into the product. The effects of mechanical deformation and thermal treatments during subsequent helical pipe making processes that influence anisotropy and heterogenity, and thus the straining capacity, need to be studied in detail [4].

This paper takes a look at the influencing factors of (mainly) anisotropy and heterogeneity in spiral welded pipes. The first section treats briefly the anisotropy of the coil, used for the helical forming process. The second section discusses the influence of the forming process on the spiral welded pipe's anisotropy and heterogeneity. In the third section, the influence of flaws in spiral welds on tensile strain capacity is considered. 


\section{INFLUENCE OF PLATE ROLLING ON MECHANICAL ANISOTROPY OF THE COIL}

Thermo-mechanically processed metallic materials commonly display mechanical anisotropy [7]-[10]. This has been examined extensively, by analysing the effects of microstructural parameters and texture. Texture is responsible for the planar anisotropy of the yield strength and tensile strength [9]. The grain size and shape distributions in the rolling direction dictate the varying mechanical properties in different orientations [11]. Anisotropy in ductility, toughness and tensile strength have been reported in [8]-[10]. Authors of [12], [13] carried out multiple tests out on industrially processed coils of linepipe steel grades in the range from API $5 \mathrm{~L} X 52$ to X80. Results of tensile tests are displayed in figure 1 and 2, to demonstrate the relation between the values of the mechanical properties in a specified orientation with respect to the rolling direction.

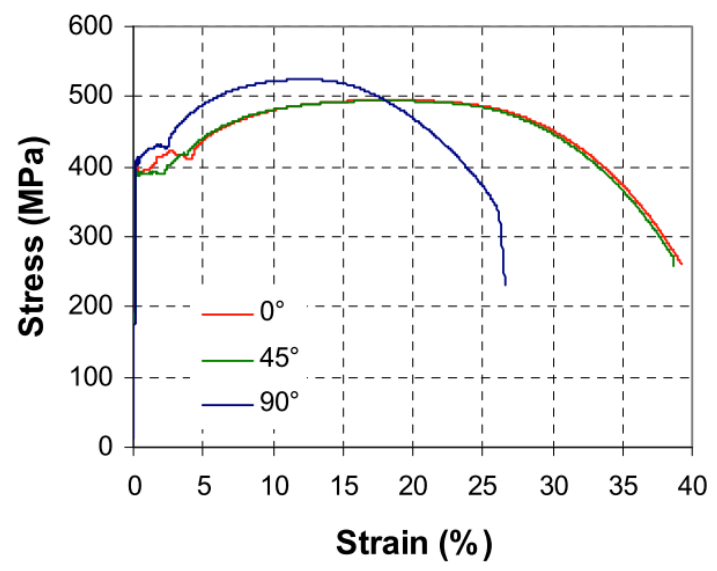

Figure 1 Stress-strain curves of samples of $X 52$ coils having different orientations with respect to the coil rolling direction [13]

Figure 1 displays the difference in strength properties and total elongation of round bar specimens of three different orientations. The curve corresponding to the specimen transverse to the rolling direction differs noticeably in comparison with the other orientations. The ductility is significantly lower, whereas yield and tensile strength are higher.

The normalized values in figure 2 were obtained by dividing each strength value by the average yield stress or tensile strength over the whole direction range. The maximum difference observed between the highest strength in the coil transverse direction and the lowest strength of the specimens oriented 30 to 45 degrees was found to be around 5 to $6 \%$. These curves help understand the strength properties of spiral welded pipes with respect to the specified forming angle, which will be elaborated in the next section.
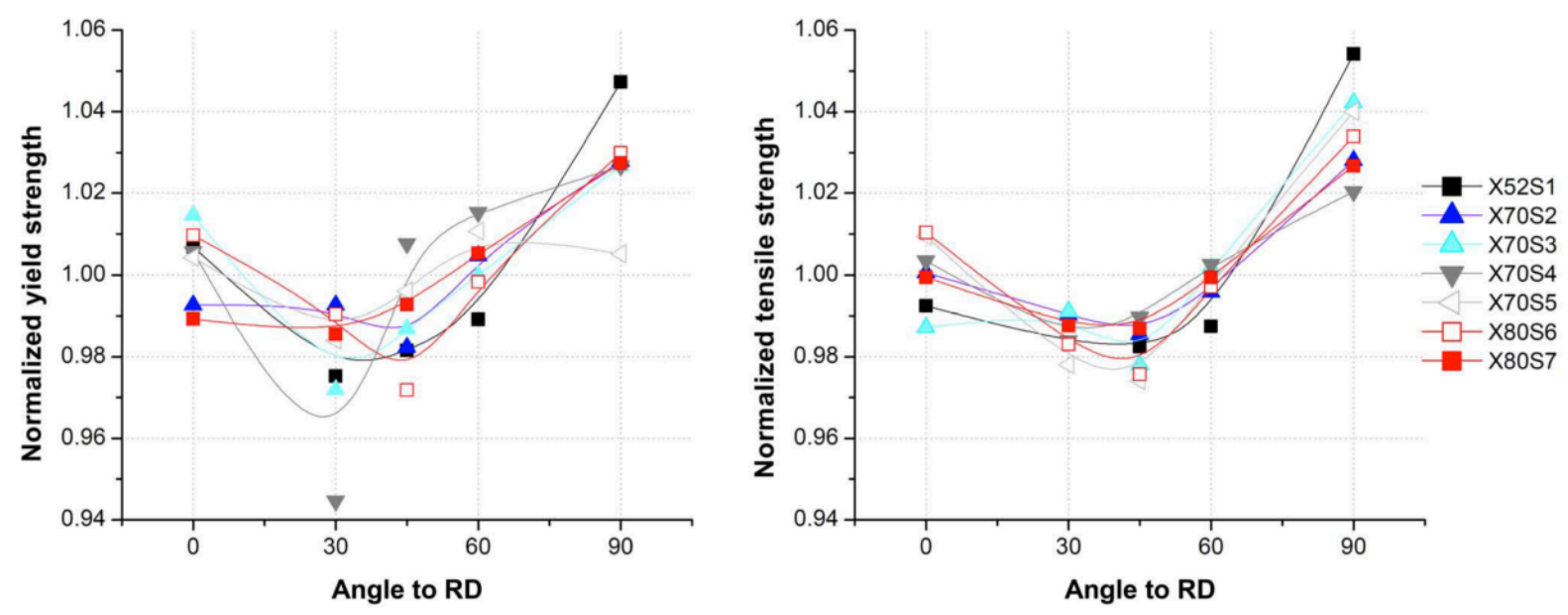

Figure 2 Normalized values of the yield stress (left) and tensile strength (right) versus tensile axis orientation [13]

From many transition curve data, N. Sanchez et al. concluded that the minimum Charpy absorbed energy corresponds with transverse to the rolling direction, as depicted in figure 3 [13]. This toughness anisotropy in the ductile region, i.e. variations in upper shelf energy (USE) of the CVN transition curves, has been commonly attributed to the presence of non-metallic inclusions [14]. 

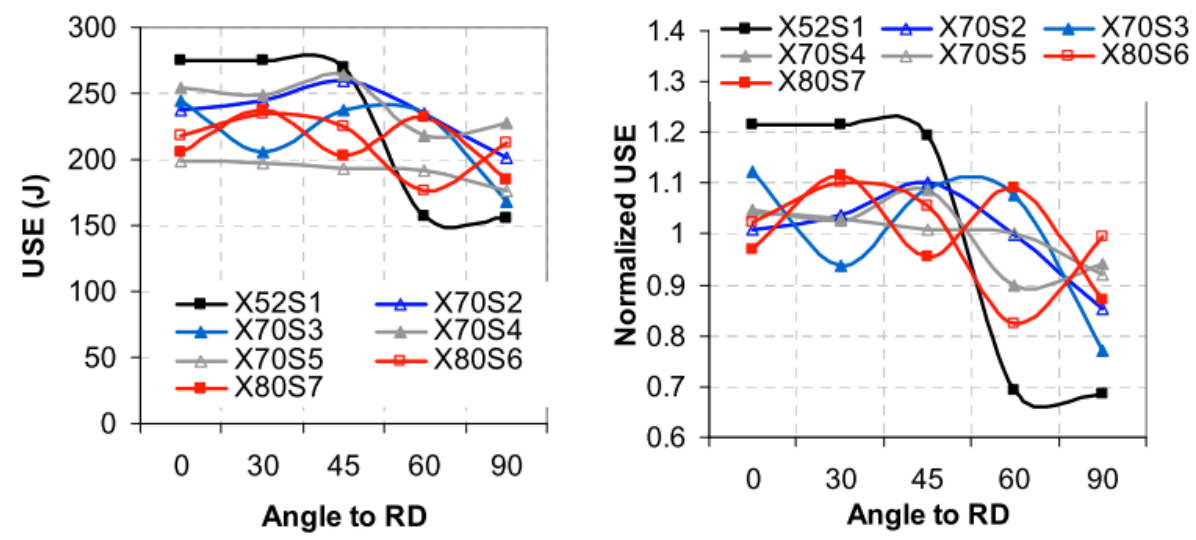

Figure 3: Left: USE of all evaluated grades. Right: corresponding average normalized USE [13]

Due to the steel-making process and the low carbon content, TMCP steels are more sensitive to HAZ softening then conventional normalized steels due to high heat input welding [15]. More of the subsequent operations, like welding, will be elaborated in §3.

\section{INFLUENCES OF THE HELICAL FORMING OPERATION ON THE MECHANICAL PROPERTIES}

In this section, the pipe forming and welding operations are explained. The sources of respectively heterogeneity and anisotropy are highlighted and quantified with available hard data or conclusions from research. The influence of anisotropy receives more attention than heterogeneity.

\subsection{Influences on global mechanical properties - mechanical anisotropy}

The helical bending operation permits the production of pipes with different magnitude diameters, starting from a one sized high-strength steel skelp. Thus, besides being cost-effective in multi-diameter pipe production, its axial mechanical properties perform generally better, i.e. because the helical weld acts as a stiffener $[4,5]$.

Figure 4 [3] illustrates the relation between the skelp and pipe orientations with the forming angle $\varphi$. The hoop strength deteriorates and the axial strength increases. The degree of tensile strain capacity depends on both the steel as the weld filler material [17]. The straining behaviour of the steel pipe material in the transverse skelp direction, marked by the fat arrow in figure 4 , is less ductile with respect to that of the longitudinal direction. This behaviour has been discussed in section 2, and illustrated in figure 1.
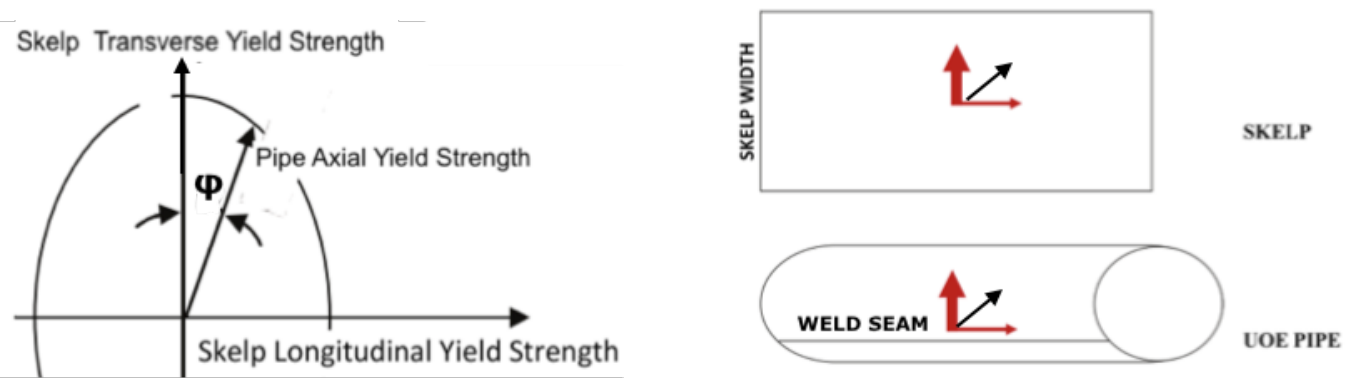

\begin{tabular}{|c|c|c|}
\hline $\begin{array}{c}\text { Skelp } \\
\text { direction }\end{array}$ & $\begin{array}{c}\mathbf{4 5}^{\circ} \text { to } \\
\text { longitudinal }\end{array}$ & transverse \\
\hline YS & Lower & Higher \\
\hline UTS & \pm Equal & Higher \\
\hline Ductility & \pm Equal & Lower \\
\hline USE & \pm Equal & Lower \\
\hline
\end{tabular}

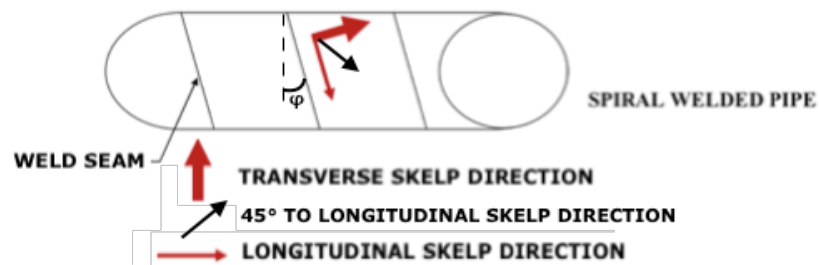

Figure 4 Left - above: Yield strengths (YS) in function of the forming angle.

Left - down: Variation of mechanical properties in comparison to those of the longitudinal skelp direction.

Right: Principal directions (red arrows) of material anisotropy [3] 
Knoop and Sommer presented statistics on mechanical, chemical and dimensional properties of spiral welded pipes [16]. They verified on a large scale the yield strength in longitudinal and transverse direction of SWP, as well as the difference in work hardening, due to the Bauschinger effect. Their results indicated that the $\mathrm{Y} / \mathrm{T}$ ratio is always higher in longitudinal direction. This means that circumferential expansion of the pipe experiences higher work hardening, an advantage if the pipe should expand in case of dimensional control or hydrostatic testing. However, the most critical issue is that this circumferential direction, which normally experiences the highest load (hoop stress), would have the weakest toughness and strength compared to other orientations [10], [12]. Consequently, this increases the chances of in-service fractures [18], [19]. Joo et al. assessed the potential causes for the orientation-dependence of toughness based on published work, in order to understand this phenomenon. The three factors connected to toughness anisotropy of steel skelps were highlighted in their work: non-uniform distribution of inclusions with various sizes and shapes, microstructural anisotropy with banding and/or elongated grains with some work of fracture and non-random crystallographic texture [20].

Work hardening behaviour in the pipe axis orientation is very important for strain-based designs, because greater work hardening rate provides a higher resistance to strain localization. Bian et al. conducted tensile tests on aged, hydrotested or expanded SWPs and longitudinal welded pipes to obtain the Y/T ratio. Data in table 1 indicates mechanical properties of X80 grade steels in terms of yield strength (YS), ultimate tensile strength (UTS) and work hardening or Y/T ratio of the spiral line pipe in comparison with a UOE pipe [21]. This table is provided as an example of the differences in yield strength, ultimate tensile strength and yield-to-tensile ratio between two kinds of pipelines. Lower YS in UOE pipes makes it simpler to achieve overmatching of girth welds.

Table 1 Round bar specimen tensile testing in the two main directions of spiral welded- and UOE-pipes [21]

\begin{tabular}{c|c|c|c|c|c|c|c}
\multicolumn{2}{l|}{} & \multicolumn{4}{c|}{ Hoop direction, averages } & \multicolumn{3}{c}{ Longitudinal axis direction, averages } \\
\hline Pipe & Test condition & YS, MPa & UTS, MPa & Y/T & YS, MPa & UTS, MPa & Y/T \\
\hline $\begin{array}{c}\text { Spiral } \\
\text { welded }\end{array}$ & Hydrotested & 546 & 640 & 0.85 & 579 & 656 & 0.88 \\
\hline UOE & after expansion & 617 & 679 & 0.91 & 566 & 647 & 0.88
\end{tabular}

3.2 Influence on local mechanical properties - Heterogeneity

\subsubsection{Bending of the skelp}

A roll bending system shapes the actual helical wound pipe. Welding is not considered in this subsection. When the flattened skelp is subjected to this forming process, the edges of the strip tend to flare out and result in a peak at the weld. To counter this behaviour, the edge of the strip is deliberately bent upwards, i.e. towards the inner diameter of the pipe, in order to ensure optimal closure of the mating surfaces after the pipe forming. The amount of edge folding must be adjusted depending upon the grade and gauge of the skelp [22]. During the subsequent operations the material experiences work hardening. Due to load reversals the Bauschinger effect will possibly affect the final strength [23], [24]. Therefore, a local zone at some offset from the edge contains lower transverse to rolling yield strength than neighbouring material along the transverse to rolling orientation. So its seems that manufactures optimise this edge bending to avoid peaked welds, but neglect the possible detrimental consequences when the final produced SWP is not post-treated by means of e.g. hydro expansion.

\subsubsection{Helical seam welding processes}

Two kinds of helical forming operations exist, called one-step and two-steps production processing of helical welded pipelines. Both differ in how they deal with the welding part of the production. The one-step process handles all welding operations - at both in and outside diameter-wise - at approximately the same point, so no extra welding process is carried out at a distant point in the production line. To speed up production, the two-step process on the other hand first performs tack welding in the pipe forming machine, which serves as a backing to weld and is fully remolten in the second step [25]. A plasma cutter divides sections of helical formed pipe to multiple finish welding stations, where submerged arc welding (SAW) heads fill internally and externally the helical seam of the pipes with a filler weld metal. This explains why two-steps-processes produce spiral welded pipes at a higher rate than one-step processes. Because welding heat input only affects the edges of the plate, it causes heterogeneity in both production types, but possibly both in different quantities. This could influence the toughness behaviour at the weld zone, but [26] points out that a HAZ softening of $3 \%$ does not significantly alter the toughness. Instead, the behaviour depends strongly on the weld strength overmatch with respect to the parent material. 
When a spiral welded pipe is subjected to an axial deformation, a crack present in a spiral weld undergoes two main stress components, the first one perpendicular to the weld and the second one parallel to the weld. It suffers from mixed mode loading, in contrast with mainly mode I loading of a crack in a girth weld of a UOE pipeline. The crack opening displacement (COD) is a measure for the crack tip loading of the pipe. It can be divided in a mode I, and mode III COD in case of defects in spiral welded pipelines. The stress perpendicular to the spiral seam drives the mode I COD, and promotes the opening of the crack. Mode III COD or out-of-plane shear, caused by stress along the weld, partially adds an extra detrimental effect to the toughness properties the defective weld. The question remains how much this actually affects the toughness, taken the whole anisotropic background of the pipe into account. Figure 5 illustrates the mixed mode loading of a crack in a spiral seam.
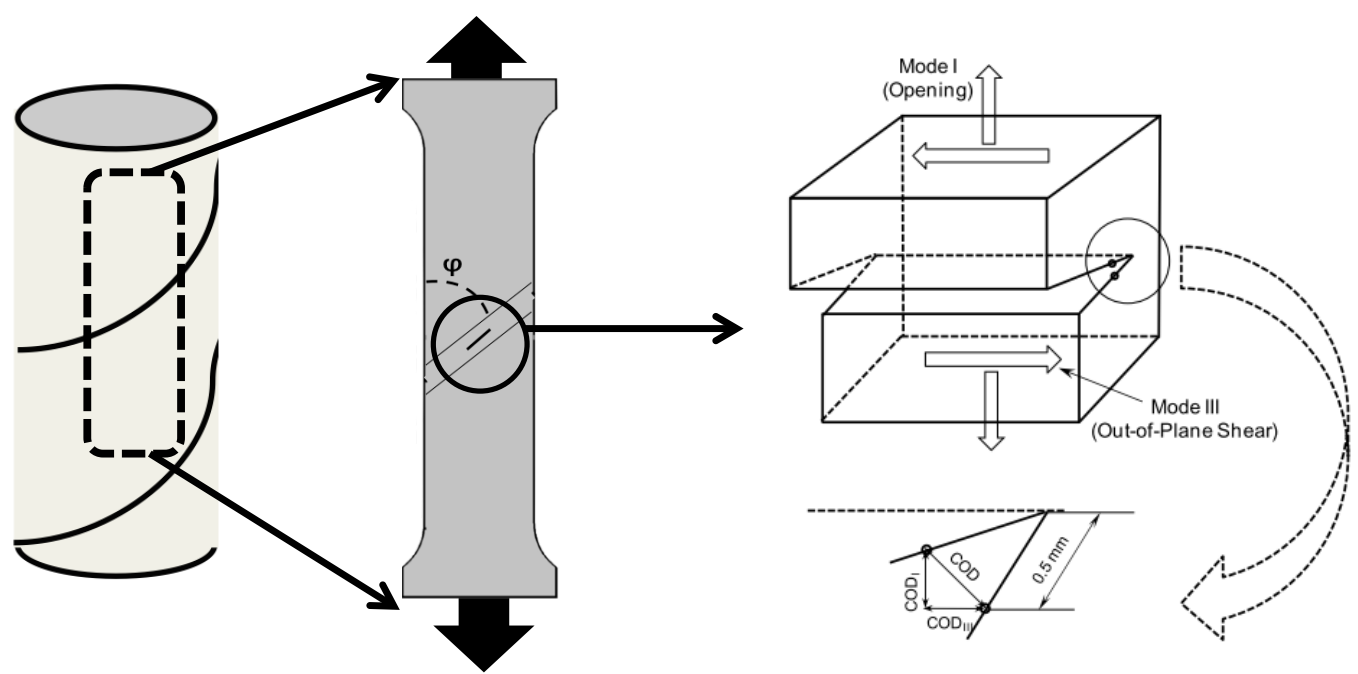

Figure 5: Left: A part of spiral welded pipeline

Middle: a spiral curved wide plate with a notch along the weld centerline

Right: Mode I/III mixity and COD indication

Ductile tearing resistance characterizes the resistance against slow stable crack extensions [27]. Tearing resistance curves express COD or J-integral values, as a function of crack extension. Both COD and $\mathrm{J}$ integrals results have to be analysed with caution, as authors of [28] point out that COD toughness exhibits less sensitivity to mixed mode loading than the J-integral. In case of SWPs, the contribution of mode III to the design of R-curves causes some ambiguities. Mode I COD is considered as the most common loading and fracture mode, a well-studied parameter in academic and industrial sector [5]. Current research conducted by [29]-[32] investigates the mode I/III loading. Large forming angles can increase the mode III component. Lower forming angles cause similar crack driving forces of spiral weld flaws to girth welds, while higher forming angles can give rise to significantly lower crack driving forces for spiral weld flaws in comparison to girth weld flaws, as can be seen in figure 6 [5], [33]. It should be mentioned that the results, as shown in figure 6 originated from a simulation that used a Von Mises isotropic hardening model for all materials, and also material anisotropy was not considered. Figure 6 displays solely the influence of the forming angle on the crack driving force acting on a spiral weld flaw, in comparison to the crack driving force acting on a flawed girth weld in function of remote strain. In addition to that, pressurised and nonpressurised loading conditions on API 5L X80 30" and 48" diameter pipelines with two different weld offsets have been considered in the simulations. It is found that internal pressure significantly increases the mode I component, and a higher forming angle results in an increased mode III component. At lower forming angles $\left(<23.5^{\circ}\right)$, the spiral and girth welds will have similar strain capacities. For case $A$, where the spiral forming angle was $39.5^{\circ}$, the mode III is dominant without pressure. In the pressurized simulation, mode I displays higher values than mode III. Case B, a spiral welded pipe with a forming angle of $23.5^{\circ}$, shows a domination of the mode I crack driving force when pressure is applied, like case $A$. Without pressure in case B, a high mode mixity appears. Thus for both forming angles, the pressure promotes the mode I component [5]. 

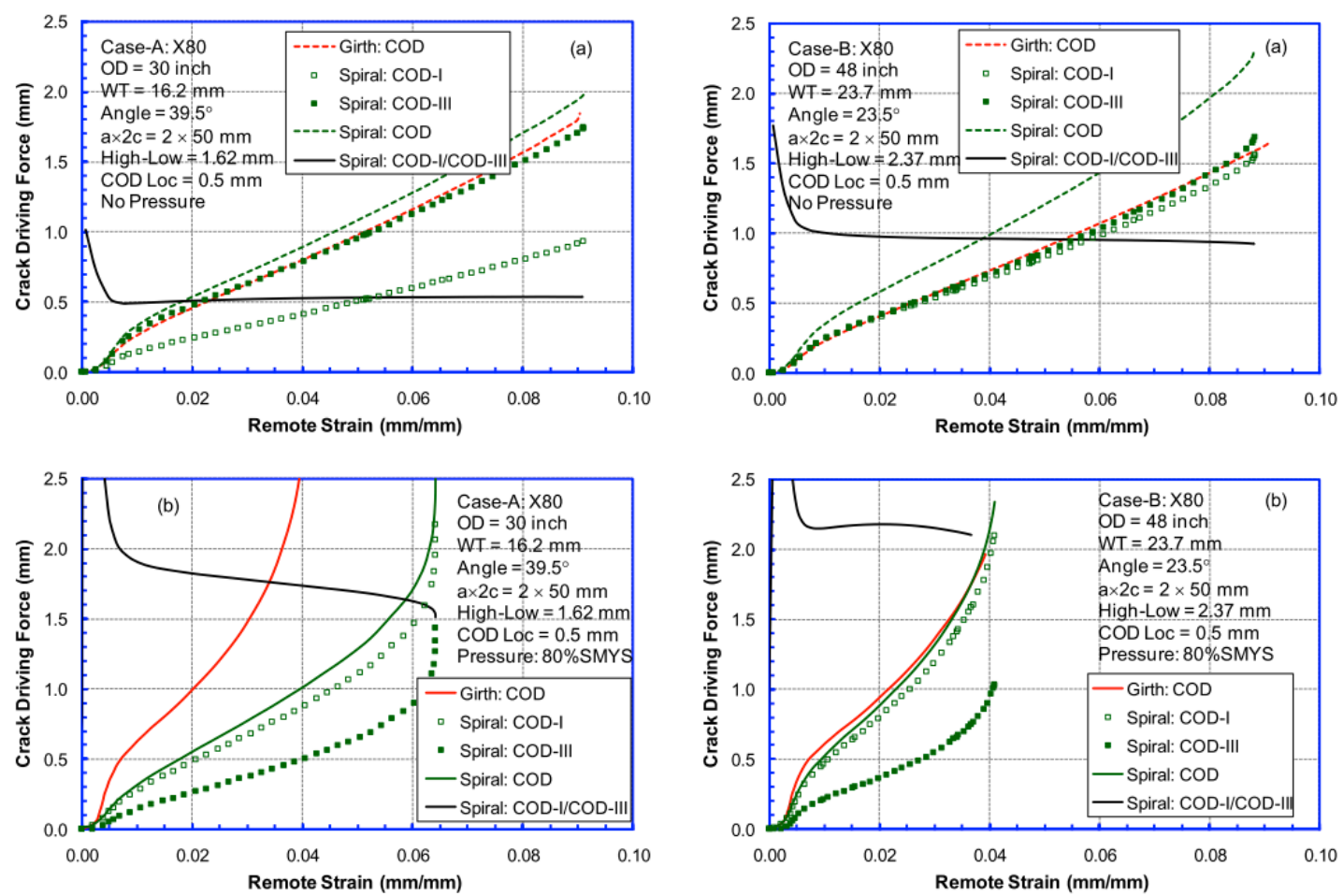

Figure 6 Mode I and III crack drving force for spiral and girth weld flaws.

Top: without pressure. Bottom: with pressure [5]

Of course, mechanical anisotropy has an influence on crack driving force and the strain capacity. Van Minnebruggen et al. [33] concluded from FEA that specific combinations of directional anisotropy and helical forming angles can have a detrimental effect on straining capacity. The COD rises with respect to an isotropic pipe, due to the anisotropy. Contrary to what was described as a possible important influencing factor earlier in this paper, they also concluded that through thickness characteristics have only a secondary effect to the degree of mode mixity upon plastic deformation.
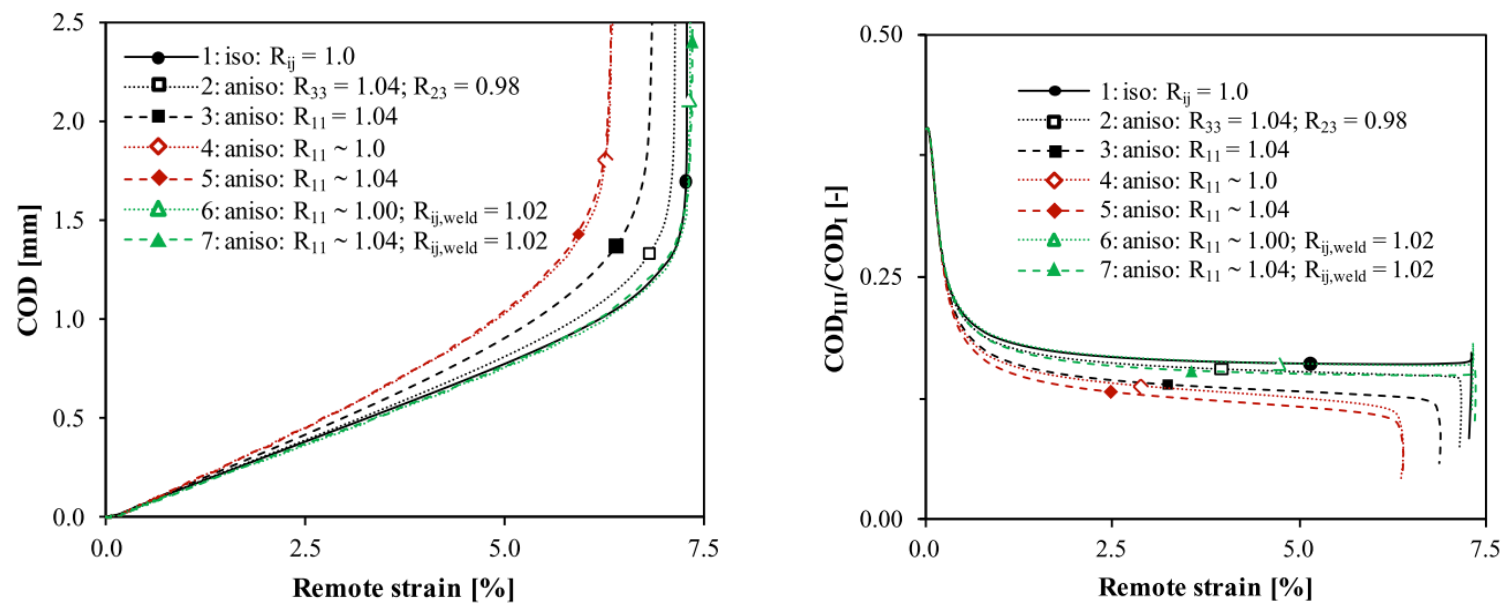

Figure 7 Left: influence of anistropy on crack driving force behaviour

Right: Ratio of mode III to mode I COD (mode mixity) as function of remote strain [33]

The $R_{\mathrm{ii}}$ an $R_{\mathrm{ij}}$ values in figure 7 should be derived from tensile and shear testing to determine the parameters of Hill's 1948 anisotropic yield criterion (1), an extension to the well knownisotropic Von Mises yield criterion. The parameters $F, G, H, L, M$ and $N$ are expressions, in function of different $R_{i j}$-values. These $\mathrm{R}_{\mathrm{ij}}$ 's display the ratios of shear $\sigma_{i j}$ or tensile $\sigma_{i i}$ stress with respect to a reference yield stress $\sigma_{0}$, given in equation (2).

$$
\sigma_{H i l l}=\left[F\left(\sigma_{11}-\sigma_{22}\right)^{2}+G\left(\sigma_{22}-\sigma_{33}\right)^{2}+H\left(\sigma_{33}-\sigma_{11}\right)^{2}+2 L \sigma_{23}^{2}+2 M \sigma_{13}^{2}+2 N \sigma_{12}^{2}\right]^{\frac{1}{2}}
$$




$$
R_{i i}=\frac{\sigma_{i i}}{\sigma_{0}} ; R_{i j}=\sqrt{3} \cdot \frac{\sigma_{i j}}{\sigma_{0}}
$$

The ratios in formula (5) and figure 7 with subscript ' 11 ' refer to the through thickness direction (TTD); with subscript '22' to longitudinal to rolling direction; with subscript ' 33 ' to transverse to rolling direction (TRD). Figure 7 displays COD-values from 7 different cases. Case 1 represents the isotropic material response. Cases 2 and 3 show 4\% planar anisotropy of equal LRD with TTD or respectively TRD characteristic in the base material. The weld can be considered as an evenmatch with the LRD. Cases 4 and 5 incorporate the same TTD variation as analysis 2 and 3 . The reference yield stress here is recalculated to obtain an equivalent pipe hoop yielding as for the reference isotropic case by using plane stress assumptions and transformation equations of the stress components. The weld strength equals that of the isotropic case, to investigate the influence of anisotropic response. Cases 6 and 7 recalculate the weld characteristics to obtain an evenmatch of weld material related to the pipe axial strength while maintaining the base material characteristic form cases 4 and 5 [33].

Simulation results of those cases, displayed in figure 7, show that strain capacity in case 3 decreased more than it did in case 2. This indicates the influence of through thickness properties on the crack driving force. The planar anisotropy of $4 \%$ of higher NRD yield strength of a X80 grade steel in the simulation seems rather low. An investigation of mechanical thickness properties of X60 grade TMCP steels resulted in thickness yield strengths of $476.4 \mathrm{MPa}$ to $533 \mathrm{MPa}$, or a $\mathrm{R}_{11}$ value of 1.15 to 1.29 [15]. Cases 4 and 5 both have an equal rise in COD, which could denote that difference of NRD magnitudes has no significant influence. The last two cases cannot be distinguished from the isotropic reference case. This suggests that the weld strength mismatch in axial direction is the key parameter governing strain capacity, for the studied simulations. Case 2 to 5 introduced an undermatching weld and thus led to an increase of the crack driving force [33].

The relative contribution of the mode III COD to the crack driving force, seen on the right in figure 7 , decreases as plasticity develops in the vicinity of the crack tip. The mode mixity decreases with increasing weld strength undermatch for the FEA simulations [33]. It should be noted that here the weld geometry and possible misalignment, along with varying forming angle, HAZ effects and weld strength overmatch has not been taken into account.

\section{CONCLUSIONS}

Spiral welded pipes are still faced with unresolved issues with respect to longitudinal tensile strain characteristics and crack driving force behaviour. They contain different local and global directional mechanical properties, which originated from rolling, heat treatments, coiling, bending, shaping and welding. These operations, which were discussed more or less briefly in this paper, influence the overall performance of the pipe, both strain capacity and crack driving force. With respect to strain capacity, isotropic models showed similar performances to UOE pipes in case of low forming angles, while simulations with higher forming angles indicated a rise of the mode III crack driving force component. In addition, internal pressure affects higher strain capacities of spiral welded pipes. The crack driving force in general deteriorates in comparison to UOE pipes, but there is a decrease of the relative contribution of the mode III component in vicinity of the crack tip, due to the large plasticity. Additionally, it seems at first sight that through thickness properties, introduced in the hot rolling process, have secondary effects with respect to the crack driving force.

Lack of published data - especially the absence of experimental test results -make future research inevitable. Simulations, like cited in this paper, can give a first good feel impression, but do not take all anisotropic influences from subsequent production steps into account. Characterizing the (preferably) helical and girth weld zones for FEA are the next step to see more detailed or global effects of HAZ softening and overmatching on the overall tensile strain capacity of spiral welded pipelines.

Current research at Ghent University consists of (i) the execution of various experiments with wide plate specimens containing a spiral weld; (ii) a clarification of the specific influence from helical welding on local mechanical anisotropic properties, by means of hardness measurements, Results from standardized tensile and tearing resistance tests (SENT) are used as input for simulation and validation of developed FEMs.

\section{ACKNOWLEDGEMENTS}

The authors would like to acknowledge Arcelor Mittal R\&D Ghent (Belgium) / OCAS NV for their financial support. 
[1] H. Zhiqian, "The progress of the greatest gas pipeline project in China," in Proceedings of the International Pipeline Conference, IPC, 2002, vol. A, pp. 183-188.

[2] N. Snow, "US Senate passes bill approving Keystone XL pipeline project," Oil \& Gas Journal, 2015. .

[3] G. Heiberg, A. Eltaher, P. Sharma, and P. Jukes, "Spiral Wound Linepipe for Offshore Applications," in OTC 21795, 2011, pp. 1-11.

[4] K. Van Minnebruggen, W. De Waele, R. Denys, and P. Thibaux, "Strain Based Design Considerations for Spiral Welded Pipelines," Sustainable Construction and Design, vol. 3, no. 1, pp. 44-51, 2012.

[5] M. Liu, Y. Wang, and L. Collins, "Tensile Strain Capacity of Spiral Pipes," in IPC2012-90661, 2012, pp. 1-7.

[6] W. C. Kan, M. M. Zhang, D. B. Lillig, S. T. Barbas, M. L. Macia, and N. E. Biery, "Strain-Based Pipelines : Design Consideration Overview," vol. 8, pp. 174-181, 2008.

[7] D. Raabe, P. Klose, B. Engl, K. P. Imlau, F. Friedel, and F. Roters, "Concepts for integrating plastic anisotropy into metal forming simulations," Advanced Engineering Materials, vol. 4. pp. 169-180, 2002.

[8] J. B. Ju, J. S. Lee, and J. il Jang, "Fracture toughness anisotropy in a API steel line-pipe," Materials Letters, vol. 61, pp. 5178-5180, 2007.

[9] N. S. Mouriño, R. Petrov, J. H. Bae, K. Kim, and L. A. I. Kestens, "Texture dependent mechanical anisotropy of X80 pipeline steel," in Advanced Engineering Materials, 2010, vol. 12, pp. 973-980.

[10] K. Kim and J. H. Bae, "Metallurgical and Process Parameters for Commercial Production of High Toughness Api-X80 Grade Hot Rolled Strips," Ipc2008: Proceedings of the Asme International Pipeline Conference - 2008, Vol 3, pp. 167-173|r795, 2009.

[11] L. Delannay and M. R. Barnett, "Modelling the combined effect of grain size and grain shape on plastic anisotropy of metals," International Journal of Plasticity, vol. 32-33, pp. 70-84, 2012.

[12] C. M. Spinelli, G. Demofonti, a Fonzo, a Lucci, J. Ferino, M. Di Biagio, V. Flaxa, S. Zimmermann, C. Kalwa, and F. M. Knoop, "Full Scale Investigation on Strain Capacity of High Grade Large Diameter Pipes," pp. 14-26, 2011.

[13] N. Sanchez, D. Van Hoecke, and M. Liebeherr, "Mechanical Anisotropy of Hot Rolled Line Pipe Steel Coil," Volume 3: Materials and Joining, p. 407, Sep. 2012.

[14] ASM Handbook, Fractography. ASM International, 1998.

[15] M. M. Salama, "Through-Thickness Properties of TMCP Steels," Journal of Offshore Mechanics and Arctic Engineering, vol. 126, no. 4, p. 346, 2004.

[16] F. M. Knoop and S. G. Gmbh, "Manufacturing and Use of Spiral Welded Pipes for High Pressure Service - State of the Art," in IPC04-0257, 2004, vol. 86, pp. 1-9.

[17] S. Hertelé, W. De Waele, R. Denys, M. Verstraete, K. Van Minnebruggen, and A. Horn, "Weld Strength Mismatch in Strain Based Flaw Assessment: Which Definition to Use?," Journal of Pressure Vessel Technology, vol. 135, no. 6, p. 061402, Oct. 2013.

[18] D. Stalheim, K. Barnes, and D. McCutcheon, "Proceeding of international symposium on Microalloyed steels for the oil and gas industry," 2007, p. 73.

[19] K.-B. Kang, J. H. Bae, and W. Y. Choo, "Proceedings," in Proceedings of the 4th International conferece on Pipeline Technology, vol.4, 2004, p. 1689.

[20] M. S. Joo, D. W. Suh, and H. K. D. H. Bhadeshia, "Mechanical Anisotropy in Steels for Pipelines," ISIJ International, vol. 53, no. 8, pp. 1305-1314, 2013.

[21] Y. Bain, C. Penniston, L. Collins, and R. Mackenzie, "Evalution of UOE and Spiral-Welded Line Pipe for Strain Based Designs," in Proceddings of the 8th International Pipeline conference, 2010, pp. 110.

[22] L. E. Collins, F. Hamad, M. Kostic, and T. Lawrence, "Production of High Strength Line Pipe Steel by Steckel Mill Rolling and Spiral Forming," in Frontier Pipe Research Unit, IPSCO, 2013, p. 17.

[23] R. Sowerby, D. K. Uko, and Y. Tomita, "A review of certain aspects of the Bauschinger effect in metals," Materials Science and Engineering, vol. 41. pp. 43-58, 1979.

[24] A. Abel and H. Muir, "The Bauschinger effect and discontinuous yielding," Philosophical Magazine, vol. 26. pp. 489-504, 1972. 
[25] B. Ouaissa, J. Brozda, M. Pérez-Bahillo, S. Bremer, and W. De Waele, "Investigations on Microstructure, Mechanical Properties and Weldability of a Low-Carbon Steel for High Strength Helical Linepipe," in JTM2009-002, 2009, no. May 2009, pp. 1-16.

[26] K. 'Van Minnebruggen, M. a. Verstraete, S. Hertelé, J. Van Wittenberghe, P. Thibaux, R. Denys, and W. De Waele, "Finite Element analysis of Crack Driving Force and mode mixity for Spiral Pipe Seam Weld Flaws.pdf," in 6th International Pipeline Technology Conference, 2013, p. 14.

[27] W. Brocks and P. Anuschewski, "Parametrizing ductile tearing resistance by four parameters," Engineering Fracture Mechanics, vol. 71, no. 1, pp. 127-146, Jan. 2004.

[28] a Pirondi and C. Dalle Donne, "Characterisation of ductile mixed-mode fracture with the crack-tip displacement vector," Engineering Fracture Mechanics, vol. 68, no. 12, pp. 1385-1402, Aug. 2001.

[29] B. S. S. Chandra Rao, M. Srinivas, and S. V. Kamat, "The effect of mixed mode I/III loading on the fracture toughness of Timetal 834 titanium alloy," Materials Science and Engineering: A, vol. 476, no. 1-2, pp. 162-168, Mar. 2008.

[30] S. Srinivas, S. V. Kamat, and P. R. Roa, "Influence of mixed mode I/III loading on fracture toughness of mild steel at various strain rates," Materials Science and Technology, vol. 20, no. 2, pp. 235-242, 2004.

[31] J. H. Yan, M. A. Sutton, X. Deng, Z. Wei, and P. Zavattieri, "Mixed-mode crack growth in ductile thinsheet materials under combined in-plane and out-of-plane loading," International Journal of Fracture, vol. 160, pp. 169-188, 2009.

[32] S. Liu, Y. J. Chao, and X. Zhu, "Tensile-shear transition in mixed mode I/III fracture," International Journal of Solids and Structures, vol. 41, pp. 6147-6172, 2004.

[33] K. Van Minnebruggen, S. Hertelé, M. Verstraete, P. Thibaux, J. Van Wittenberghe, R. Denys, and W. De Waele, "Influence of Anisotropy on Flaw Acceptability in Spiral Welded Pipe Sections," vol. 9, pp. 539-545, 2013. 